\title{
Nothing to Fear but Fear Itself: Perceptions of Job Security in Australia after the Global Financial Crisis
}

\author{
Kler, $\mathbf{P}^{\mathrm{a}}$., Leeves, $\mathbf{G}^{\mathrm{b}}$. and Shankar, $\mathbf{S}^{\mathrm{c}}$. \\ ${ }^{\text {a }}$ Department of Accounting, Finance and Economics, Griffith University, Australia \\ ${ }^{\mathrm{b}} \mathrm{School}$ of Business, Monash University Malaysia \\ ${ }^{\mathrm{c}}$ School of Business, University of Western Sydney, Australia.
}

Email:

s.shankar@uws.edu.au. Phone: +610296859372. Fax: 610296859105

\begin{abstract}
Large scale major events change people's perceptions. The effects of the global financial crisis on workers' anxiety are examined using panel data from Australia. Australia presents a unique opportunity to estimate anxiety effects as it emerged from the crisis period without enduring a recession and the economy rebounded very quickly. Our estimates focus on workers who are overeducated and their perceptions of job security; this group are known to have lower levels of satisfaction with job security and so offer a baseline estimate from which to evaluate changes associated with the crisis. We identify a workers level of commitments and responsibilities to be important in determining anxiety effects. The results support this contention; partnered workers exhibit significantly lower satisfaction with security after the crisis and this is increased if children are present. A more objective assessment of their employment stability and a possible tightening in financial conditions for a short period immediately following the crisis were examined and did not seem cause for increased concerns, suggesting these are more likely to be anxiety effects.
\end{abstract}

Keywords: Global financial crisis, Job security, Overeducation, Partnered workers. 


\section{Introduction}

The IWPR/Rockefeller survey, a survey of a representative sample of Americans conducted in late 2010 found that $71 \%$ of males believed young married couples had somewhat or a lot less economic security than ten years earlier. The response to the same question in 2007 was 33\% (Hayes and Hartmann 2011). Evidence such as this is used to suggest that a major event like the global financial crisis (GFC) generates changes in people's perceptions of the security of work and job stability in the future. Deaton (2012) suggests that the link between objective changes in financial circumstances and wellbeing is moderated through individual assessments and perceptions of the implications of these changes. In particular, he examined individual responses to the events of the GFC in 2008 and noted how fear of future unemployment may well be driving the observed changes in wellbeing. He also found that by the end of 2010 the declines had largely been erased even though unemployment remained high. This prompted him to describe wellbeing measures as good indicators of short-term anxiety. Similar findings were reported by Graham et al. (2010) who find that daily averages of happiness scores climbed quickly after the GFC recession plateaued in the US in early 2009 and reached higher levels by June 2009 relative to January 2008. Again, the patterns are attributed to a sharp rise in levels of optimism rather than changes in the actual economy.

Further evidence exists of the relationship between changes in the economy and individual perceptions of these changes. Clark et al. (2010) find that a rise in unemployment leads to a decline in wellbeing for those who remain employed, at least for males, and particularly for those who feel relatively secure in their jobs. Indeed, the authors suggest that the negative externalities of rising unemployment for the employed are related to the degree of job security. In a recent study, Blanchflower et al. (2013) confirmed a significant contemporaneous negative effect between unemployment and wellbeing, using cross country regression evidence for a set of European countries. They extended the analysis to examine 
periods of banking crises. The variable identifying banking crises was found to be a significant and relatively large negative determinant of wellbeing, above and beyond the effect of unemployment, when a crisis period covered a three year timespan. The effect was not present when the crises periods were restricted to one or two years. A bank crisis had rather longer lasting effects than changes in the aggregate unemployment rate. The crises identified included the GFC period for almost all countries. If they eliminated the 2008 period, the result, whilst weaker remained significant. Given that most individuals are not directly linked to events occurring in the banking sector, it is more likely that discussion and speculation in the media will be the channel for banking crises effects on average wellbeing (Deaton 2012).

Other studies have also found examples of dramatic major events causing changes in individual wellbeing for those not directly affected by the events. Pesko (2013) identified greater levels of stress and an increased likelihood of smoking as impacts of the 9/11 attacks on people in the USA. Moreover, the likelihood of smoking remained higher for at least two years after the events of 9/11. Metcalf et al. (2011) reported that the 9/11 attacks reduced life satisfaction of people in the UK. Taken together, these studies illustrate how individual wellbeing can be affected for those who have no personal connection to major events themselves. In some cases, these events seem to have a long lasting impact on behaviour and wellbeing.

This paper examines the longer term impact of the GFC on individuals who are overeducated. Overeducated workers are not fully utilising the education they have attained in the labour market. Existing evidence indicates that the overeducated are less happy than other workers (McGuinness 2006, Fleming and Kler 2008, Caroleo and Pastore 2011, Piper 2012), and this includes both general wellbeing (life satisfaction) and their work (job satisfaction). Studies which have analysed work satisfaction in more detail find that overeducated workers are 
particularly less satisfied in their perception of job security than their counterparts who have the education level appropriate for the job (Fleming and Kler 2008, Piero et al. 2011). This gives us a starting point to conduct our analysis as we expect prior to the GFC this group to report lower levels of satisfaction and this is indeed the case. Then we can compare how relative levels change after the advent of the GFC.

Differences in perceptions of job security appear to be a major reason for reported differences in wellbeing. For instance, job security appears to be more important for wellbeing than the type of contract under which a worker is employed (Origo and Pagani 2009). Thus, whilst workers on temporary and permanent contracts exhibited no differences in overall wellbeing, permanent workers who felt insecure were less happy than temporary workers who felt secure in their jobs. The relationship at the individual level between overeducation and wellbeing may change over time in response to changes in the economy. There is evidence that the impact of overeducation on life satisfaction might be subject to social norm effects in a manner similar to unemployment (Clark et al. 2010). Specifically, the impact of overeducation on life satisfaction decreases as overeducation levels increase because individuals feel less unhappy when there are more people in similar circumstances. Piper (2012) analysed young workers in the UK for the periods 1997-2000 and 2002-2007, a period during which more of this group become overeducated and reported that overeducation's impact on life satisfaction faded. This decline is argued to be an indicator that some of the unhappiness comes from comparison with others.

This paper analyses the perceptions of job security of overeducated and non-overeducated ${ }^{1}$ male workers in Australia between 2001 and 2011. Australia makes for a unique quasi

\footnotetext{
${ }^{1}$ Overeducation is defined via the Job Analysis/Objective method (see Hartog, 2000 for a greater elucidation of this method). In brief, an overeducated worker is an individual who holds paper qualifications above and beyond the minimum required to do the job they are employed in. The non-overeducated individuals include not just those with paper qualifications required to do their job but also the undereducated (i.e. those undertaking their
} 
'natural experiment' as it did not experience a recession during the GFC unlike other OECD countries. The GDP growth rate for the year to the June quarter of 2008 was $2.7 \%$. This fell to $0.6 \%$ for the year to the June quarter of 2009 but recovered to $3.3 \%$ for the year to June 2010. There was never a negative growth rate throughout the period. However, during this period there was a time of some weakening in the household sector (RBA 2008). The growth rate of consumer spending fell to $0.1 \%$ as the Australian economy was not immune to the global tightening in financial conditions and higher petrol prices. Indeed a composite index of consumer sentiment fell below long-run average levels (100) but remained above levels seen during the deep recession of the early nineties ${ }^{2}$. This changed in 2009, as household real disposable income rose by over $5 \%$ per annum and dwelling prices increased by approximately 7\% (RBA 2009). As a result, there was a very large swing in consumer confidence to near record index levels of 120 . The index was more volatile during 2010 but remained in positive levels and above trend. Nevertheless, the central bank noted that households remained cautious, with mortgage debt growing at much lower levels than the decade earlier and credit card debt flat during 2010.

The labour market remained relatively strong. The unemployment rate going into the recession in 2007 stood at $4.4 \%$ and rose to a high of 5.6\% in 2009 before declining to $5.2 \%$ in 2010. The unemployment rate was higher (5.9\%) in 2003 when the economy was growing at approximately $1 \%$ per annum. By 2010 full-time employment was higher than in 2008 . The only major sector to show a decline in employment was manufacturing, losing 20,000 jobs between August 2009 and August 2010. Over the same period, professional, technical and scientific services sector grew by 60,000 jobs. Moreover, according to business surveys,

job without the minimum educational requirements to do their job). This group is commonly made up of those with greater levels of experience promoted into managerial occupations. As such, their 'non-job match' is not commonly seen as being an issue.

${ }^{2}$ The consumer sentiment index is made up of an average of the Roy Morgan Consumer Confidence Rating and Westpac-Melbourne Institute Consumer Sentiment Index. The long-run average is nornmalised to 100 and the index stood at 80 by the end of 2008 . 
hiring intentions of firms in 2009 and 2010 were above trend levels, after a brief negative period in 2008. Using Australian data during and after the GFC we can examine the effects of increased global concerns on workers job security perceptions in an economy with no technical recession and relatively modest adverse effects that were in most cases quickly reversed. This will arguably allow for the identification of anxiety effects.

Clark et al. (2010) define their fault line for spillover effects from real changes in unemployment to be along the job security dimension. We propose that the fault line for anxiety effects, defined through perceptions of job security, be along the dimension of worker responsibilities and commitments. Our justification is provided by the well-known U shaped relationship of life satisfaction with respect to age with the low point reached in the mid 40's (Blanchflower and Oswald 2007). This is most frequently attributed to the responsibilities of supporting a family and paying a mortgage that make individuals concerned about employment and career. These are sources of anxiety and will be amplified by future concerns about employability and income. Although having a partner raises life and economic satisfaction (Gandelman and Piani 2013), workers who have a partner are more likely to have, or feel they have, greater commitments compared to single workers. These workers are also likely to be less mobile than single workers and so more reliant on smaller set of alternative employment opportunities. In sum, these are workers who will be more predisposed to exhibit "general anxiety" generated by the GFC. Levels of overeducation in our data averaged $20.7 \%$ in the years $2001-2007$ and $20.9 \%$ in $2008-2011$. Thus, any changes observed over this period are unlikely to be the result of norming effects related to the number of other workers in that state (Clark 2003, Piper 2012).

In an attempt to see if any changes in overall perceptions of security are associated with their actual labour market risk, we compare their perceptions to evaluations of the chance of losing their job in the coming twelve month period. The latter being a more specific and focussed 
indicator of how the "recession" could impact upon them. In addition, we documented earlier how financial conditions in Australia were tighter for a short while after the GFC. The Reserve Bank of Australia noted in November 2008 (RBA 2008) that consumer spending had fallen by $0.1 \%$ amidst tightening financial conditions. Interest rate payments had peaked at $14.5 \%$ of disposable income. Financial stress affects wellbeing (Brown et al. 2005, Bridges and Disney 2010) and financial stress is associated with employment instability (Green and Leeves 2013). Hence, we explore the possibility that changes in domestic financial conditions may vary between the overeducated and non-overeducated and this impacts on job security concerns and other dimensions of the job satisfaction domain. We use the extent of credit card payment difficulties as an indicator of financial stress.

The rest of the paper is organised as follows. Section 2 provides a detailed look at the data and methodologies used. Results are discussed in Section 3, whilst Section 4 concludes.

\section{Data and Methodology}

Data is obtained from the first eleven waves (2001-2011) of the Household, Income and Labour Dynamics in Australia (HILDA) panel dataset. The three significant advantages of this dataset for our research is that is has a rich measure of job satisfaction (see Appendix Box 1), tracks individuals over time $\mathrm{e}^{3}$ and contains a vast array of personal, employment, family and educational variables (see Appendix Table A1 for a list of variables used in this study).

We utilise four measures of job satisfaction from the dataset. We focus on perceptions of job security, our main interest, as this is the closest dimension of job satisfaction to "anxiety" concerns (Deaton 2012). We also examine three other measures of job satisfaction: overall, pay and work itself to provide a broader picture of worker's perceptions of their jobs during

\footnotetext{
${ }^{3}$ Newer waves are replenished for attrition though the potential for attrition bias still exists.
} 
this period. These satisfaction measures are asked on an ordinal 11 point (0-10) scale and repeated annually. The use of satisfaction with job security is, given previous research obvious. The use of overall job satisfaction is also useful because it provides an insight of how a 'composite' measure of job satisfaction that utilises all information of more specific measures of job satisfaction is impacted by significant economic events. This study utilises satisfaction with pay and type of work as further measures of wellbeing, which may yield insights into changing perceptions of job satisfaction as large economic events occur.

Our other indicator of job security comes from the individual's evaluation of the chance of being sacked from their job in the next twelve months. This response is rated on a scale between 0 to 100 . To consider the possibility that financial tightening may impact on overeducated workers more acutely than others we use another variable from HILDA. Specifically, we use responses to the question "How often do you pay off all credit card monthly balances ?" This is rated from 1 - "Pays off entire balance hardly ever" to 5 - "Pays off entire balance always".

\subsection{Econometric methodology}

Given that the dependent variable (the four measures of workplace satisfaction) in this study is ordinal in nature, we utilise random effects (RE) ordered probits (with Mundlak corrections). This model has the advantage of controlling for unobserved time-invariant individual heterogeneity. As the panel used in this study is relatively short, this implies that differences across individuals rather than changes within an individual have more influence on overall job satisfaction. Thus, it is reasonable to use random effects instead of fixed effects (Lancaster, 2000).

The econometric model of overall job satisfaction has the general form: 
$y_{i t}^{*}=\mathbf{x}_{i t}^{\prime} \boldsymbol{\beta}+\varepsilon_{i t}=\mathbf{x}_{i t}^{\prime} \boldsymbol{\beta}+\alpha_{i}+v_{i t}, \quad i=1, \ldots . . N, t=1, \ldots \ldots ., 10$

where $y_{i t}^{*}$ is a latent variable indicating the unobservable level of overall job satisfaction of employee $i$ at time $t . \mathbf{x}_{i t}^{\prime}$ a vector of observable time invariant factors and time-varying factors including wages, individual socio-demographic characteristics, family and household characteristics, work related factors, information on working conditions, geographical locations, year dummies, and other control variables. $\boldsymbol{\beta}$ is a vector of coefficients and $\varepsilon_{i t}$ is the error term. The random noise component of the composite $\left(\varepsilon_{i t}=v_{i t}+\alpha_{i}\right)$ error term, that is, $v_{i t}$ is a time and individual specific error term and is assumed to be uncorrelated with the explanatory variables. The individual specific component of the composite error term, that is, $\alpha_{i}$ is assumed to be a random-component constant over time and uncorrelated with the explanatory variables. Such a strong assumption that the individual-specific error term is uncorrelated with the explanatory variable may not hold, and thus an approach proposed by Mundlak (1978) is used (by adding the within-group means of all independent variables) to resolve the issue.

The individual overall job satisfaction $\left(y^{*}\right)$ cannot be observed instead a categorical but ordered random variable $y_{i t}$ is estimated as a function of the explanatory variables and a set of cut-off points $z_{j}(\mathrm{j} \in\{0,1 \ldots ., 10\})$.

$$
y_{i t}=j \Leftrightarrow y_{i t}^{*} \in\left[z_{j}, z_{j+1}\right]
$$

The conditional probability of a given observation can be expressed as:

$$
\operatorname{Pr}\left(y_{i t}=j / x_{i t}\right)=\operatorname{Pr}\left(z_{j} \leq \mathbf{x}_{i t}^{\prime} \boldsymbol{\beta}+\varepsilon_{i t}<z_{j+1}\right)
$$




$$
=\operatorname{Pr}\left(z_{j} \leq y_{i t}^{*}<z_{j+1}\right)
$$

where $j$ in our case is overall job satisfaction score ranging between 0 and 10 . The probability of an employee choosing an overall job satisfaction level of $j$ given the explanatory variables $\left(\mathbf{x}_{i t}^{\prime}\right)$ corresponds to the region of the distribution where $y_{i t}^{*}$ falls between $z_{j}$ and $z_{j+1}$.

It is however, quite common in the literature to also employ a generalised least square (GLS) methodology to these ordinal job satisfaction measures. In this case, the dependent variable (which is a discrete ordered variable of the type aforementioned) is assumed to be a cardinal variable. Ferrer-i-Carbonell, Frijters (2004) and Clark et al. (2010) find that estimated results do not differ significantly whether one assumes happiness and/or satisfaction scores to be ordinal or cardinal. One reason for utilising the GLS method is that, compared to the random effects ordered probit method, it has the advantage of being easily interpretable as results are linearised. Nevertheless, Mavromaras et al. (2012) raises some doubt as to the uniformity of results when comparing ordinal and cardinal dependent variables. ${ }^{4}$

The random effects (RE) model can be written as

$$
y_{i t}=\alpha_{i}+\mathbf{x}_{i t}^{\prime} \boldsymbol{\beta}+v_{i t} \quad i=1, \ldots, N ; t=1, \ldots, 10
$$

where the distribution of $\alpha_{i}$ and $\varepsilon_{i t}$ are assumed respectively to be $\alpha_{i} \square$ i.i.d $\left[0, \sigma_{\alpha}^{2}\right]$ and $v_{i t} \square$ i.i.d $\left[0, \sigma_{v}^{2}\right]$. The feasible GLS estimator of the RE model, called GLS random effects estimator, can be calculated from the OLS estimation of the transformed model ${ }^{5}$ :

$$
y_{i t}-\hat{\lambda} \bar{y}_{i}=(1-\hat{\lambda}) \mu+\left(\mathbf{x}_{\mathbf{i t}}-\hat{\lambda} \overline{\mathbf{x}}_{\mathbf{i}}\right)^{\prime} \boldsymbol{\beta}+\xi_{i t}
$$

\footnotetext{
${ }^{4}$ To be more specific, Mavromaras et al. (2012) are not claiming that the studies assuming cardinality on ordered variables present misleading results, rather one needs to exercise caution when making such assumptions as there is a potential (albeit a minimal one given past research) for results to differ when ordinality and cardinality are assumed.

5 see Cameron and Trevidi (2005) (sec 21.7) for the detailed proof
} 
where $\bar{y}_{i}=\frac{1}{T} \sum_{t=1}^{T} y_{i t}, \overline{\mathbf{x}}_{\mathbf{i}}=\frac{1}{T} \sum_{t=1}^{T} \mathbf{x}_{i t}, \bar{v}_{i}=\frac{1}{T} \sum_{t=1}^{T} v_{i t}, \xi_{i t}=(1-\hat{\lambda}) \alpha_{i}+\left(v_{i t}-\hat{\lambda} \bar{v}_{i}\right)$ is asymptotically iid, and $\hat{\lambda}$ is a consistent estimator for $\lambda=1-\frac{\sigma_{v}}{\sqrt{\sigma_{v}^{2}+10 \sigma_{\alpha}^{2}}}$.

Our approach is relatively agnostic. We present random-effects ordered probit results due to their greater theoretical econometric validity, but when appropriate also present GLS results in order to present readily interpretable results. Results in Section 3 suggest that whilst similar, minute differences do exist between the two. Nevertheless, the relative merits and demerits of either methodology are beyond the scope of this paper and is left for future research.

\section{Results}

This section begins with a look at statistical results before progressing onto econometric results as described above.

\subsection{Statistical results}

In Table 1 we present some preliminary data on the unconditional relationship between our various measures of worker satisfaction for overeducated and non-overeducated before and after the GFC. The overeducated are less satisfied with all four dimensions of their employment situation, confirming earlier evidence. It is notable that, other than for "Work itself" the averages increase after the GFC. This is indicative of an economy that in real terms suffered relatively little from the GFC. However, the t-tests indicate that significant differences remain between the overeducated and non-overeducated. In the next section we 
probe a little more into the relative magnitude of these differences with more formal econometric evidence.

[Table 1 About Here]

\subsection{Econometric results}

We move to a more formal analysis of this relationship using the random effects ordered probit model with Mundlak corrections in Table 2, where each satisfaction variable is the dependent variable in the four columns of results. The coefficient estimates for overeducation and key variables related to the individual's wage, current employment status (part-time or full-time) and employment history. The main finding is that there are differences associated with the pre and post GFC periods. Before the GFC the overeducated were more dissatisfied with their work situation, except in the case of "Work Itself" satisfaction where no clear difference existed. After the GFC, the relative dissatisfaction for overall job satisfaction and pay satisfaction disappears; this was not evident in Table 1. However, overeducated males continue to have significantly lower levels of satisfaction with job security, and they are also less satisfied with the intrinsic value of the job (work itself). The regressions include year dummies to capture any trends in satisfaction levels common to all male workers.

Of the other variables, higher hourly is associated with greater overall job satisfaction and this appears to be linked to increased pay satisfaction; this remained unaffected by the GFC. Part-time workers were associated with lower levels of overall job satisfaction and job security prior to the GFC. After 2008, part-time workers levels of satisfaction on these domains were not statistically different from full-time workers. Interestingly, the accumulated experience of unemployment exerted an adverse impact on job security satisfaction in the post GFC period, though this was marginally significant.

[Tables 2 and 3 About Here] 
We now compare our results with those obtained with a GLS model. These are reported in Table 3. In general, the sign and significance of the results are unaltered. Of specific interest are the results for the job security variable, which, as with the ordered probit results, indicate the gap between the overeducated and non-overeducated was maintained after the GFC. ${ }^{6}$ The one exception is satisfaction with "Work itself". The GLS results indicate a significant lower level of satisfaction for the overeducated prior to the GFC, the estimate was negative but not significant in Table 2. However, the post GFC estimate for the effect of overeducation is consistent with the random effects ordered probit result. In addition, the wage effect post GFC is positive and significant in the GLS estimates but negative and significant with the earlier results. The GLS results do offer a more straightforward interpretation of quantitative effects than the ordered probit estimates. Hence, if an individual becomes overeducated, other things being equal, he will record a 0.15 point lower job security score (evaluated at the mean).

Thus far, we have some evidence that overeducated workers continued to be less satisfied with job security after the GFC, even though overall job satisfaction exhibited some relative improvement. We now focus on workers who would be expected to have more commitments and responsibilities. Workers who have a partner are more likely to have, or feel they have, commitments compared to single workers. These workers are also likely to be less mobile than single workers and so more reliant on smaller set of alternative employment opportunities. In sum, these are workers who will be more predisposed to exhibit "general anxiety" generated by the GFC. We repeat the analysis in Tables 2 for partnered and single workers in Tables 4 and 5.

[Table 4 and 5 About Here]

\footnotetext{
${ }^{6}$ The estimated overeducated coefficients are quantitatively similar to those reported by Piper (2012) for young overeducated workers in the UK using dynamic panel methods with life satisfaction as the dependent variable.
} 
From Table 4 we can see that, prior to the GFC, partnered overeducated workers job security concerns appear to be indistinguishable statistically from other workers. In all other cases, the partnered overeducated are less satisfied than their non-overeducated counterparts. After the GFC, just as in the full sample results, overall and pay satisfaction differences disappear. However, for job security the overeducation coefficient becomes highly significant and negative; the point estimate is larger than that for the full sample. This change in relative job security satisfaction would be consistent with partnered overeducated males being more susceptible to anxiety concerns.

We repeated the exercise using GLS estimation. For brevity, we report only the result for the overeducated variable in the second last row of results in each panel. The pattern of sign and significance is very similar. To further examine the possibility that commitments are associated with increased anxiety, we disaggregated the partnered sample into those who have children and those who do not. The last row of results in each panel present the overeducated coefficient estimates for the group of male workers who are partnered with children. The GLS estimates allow a more direct comparison. As might be expected, their relative dissatisfaction with job security after the GFC is even greater relative to nonovereducated than for all partnered males. It is noted that the coefficient estimate is over $50 \%$ greater than for overeducated workers in general in the post GFC period (Table 3). This would be consistent with this group displaying rather greater levels of anxiety or not sharing any slight increase in optimism felt by other workers.

In Table 5 we present the results for singles. Overeducated singles become relatively less concerned about job security compared to other singles after the GFC. Indeed, their security concerns became indistinguishable from other workers after the GFC. This is similar to what happens on the other dimensions of job satisfaction, except for pay where they were never 
statistically differentiated from other workers. Thus, it appears that single workers are rather less sensitive to anxiety effects than their partnered counterparts.

How do these changes in perceptions of security relate to other indicators of employment stability? We now use the information from the variable related to the chances of being sacked in the next twelve months. The averages before and after the GFC for those who are overeducated and those who are not are presented in Table 6. These figures illustrate a key point noted at the outset. Namely, Australia did not experience a technical recession during the GFC. It is evident from the full sample figures in columns two and three that in general people did not feel in any more danger of losing their jobs after the crisis period. There is a slight increase for the overeducated but for others the figure actually declines. For partnered males, the overeducated perceived their chances of losing their job to be almost the same after the GFC as before the crisis. In the case of partnered workers, before the crisis the average figures for non-overeducated was $9.99 \%$ and for those who were overeducated it was $10.72 \%$. After the GFC the figures were $8.99 \%$ and $10.71 \%$ respectively. In the last two columns, the coefficient estimates of the overeducation dummy are presented from an OLS regression containing all of the covariates used in the earlier tables, including Mundlak corrections. ${ }^{7}$ Conditional on these other variables we now find that there is a slight, but statistically significant, increase in the perception of overeducated workers being sacked of approximately $1.8 \%$, both for the whole sample and for partnered workers. In the case of partnered workers, this increase would seem very modest compared with the changes in relative perceptions of job security.

[Insert Table 6 about here]

\footnotetext{
${ }^{7}$ As the dependent variable ranges from 0-100 we assume it to be continuous.
} 
Next, we examine if the relative changes in security perceptions are linked to differences in financial circumstances between the groups. Earlier it was noted that the GFC period was associated with a tightening of conditions in the household sector and this may have had stronger spillover effects into the job domain for overeducated workers. The summary statistics of our financial stress variable (credit card payment difficulties) are presented in the lower panel of Table 6 . As with the data relating to chances of being sacked, the raw averages of the credit card balance variable improve slightly after the GFC. In this case the relative improvement is the same for overeducated and non-overeducated and this applies to the full sample and those who are partnered. We then condition on the full range of observable characteristics and their Mundlak corrections and run random effects ordered probit regressions. The results in columns three and four confirm the pattern in the raw data; there was no change in relative ability to pay off credit card balances. On the basis of the evidence presented it would seem difficult to attribute any relative increase in concerns with job security amongst those who are overeducated with changes in their domestic financial situation.

\section{Summary and Conclusion}

There is a growing interest in the welfare effects of major adverse events. Previous research has shown that the events of $9 / 11$ have impacted on the wellbeing of individuals across America and in the UK. Prolonged banking crises associated with the GFC appear to have led to sustained decreases in wellbeing in a number of countries. Earlier studies have almost exclusively concentrated on responses to questions on life satisfaction from data samples of the adult population. We complement this research by focussing on employed overeducated workers and their perceptions of job security in the wake of the GFC. Using the relatively unique situation of the Australian economy, which survived the GFC relatively unscathed and suffered no recession, allows us to identify stress and anxiety effects. We identify workers 
level of commitments and responsibilities as the 'fault line' (Clark et al. 2010) that will determine the extent of anxiety effects. Overeducated workers are known to be more prone to concerns regarding their job security and this is confirmed in our results relating to the period prior to the GFC; this gives us a baseline estimate from which to evaluate relative changes. We find that the overeducated continue to exhibit relatively less satisfaction with job security after the crisis period, even though satisfaction with pay and overall job satisfaction increase compared to non-overeducated. In particular, the extent of responsibilities and commitments were significant in determining responses after the GFC. Overeducated workers with a partner were significantly less satisfied with their job security than non-overeducated workers with a partner after the GFC and this distinction was even greater if they had children. Prior to this they were indistinguishable from other partnered workers. Because of the economic situation in Australia, the numbers overeducated over our sample period changed little and so there are unlikely to be any norming effects to bias the results.

Additional evidence supported the "anxiety" hypothesis. Partnered workers expectations of losing a job in the coming year following the GFC did not differ from other workers. Moreover, we recognised that the economy experienced a period of tightening financial conditions and allowed for this in supplementary estimations with an indicator of financial stress. However, partnered overeducated workers appeared to be under no specific domestic financial stress compared to other partnered workers. The common patterns in these more objective indicators of job instability and financial stress are supportive of the notion that these workers perceptions of events are generating more anxiety about their future.

There is a clear welfare role for government policy and central banks in terms of the management of how information is conveyed to the public through the media regarding economic prospects and forecasts of unemployment. In addition, partnered workers anxiety 
may translate into increased divorces and separations (Arkes and Shen 2013) creating further welfare losses.

\section{Acknowledgements}

This paper uses unit record data from the Household, Income and Labour Dynamics in Australia (HILDA) Survey. The HILDA Project was initiated and is funded by the Australian Government Department of Social Services (DSS) and is managed by the Melbourne Institute of Applied Economic and Social Research (Melbourne Institute). The findings and views reported in this paper, however, are those of the author and should not be attributed to either DSS or the Melbourne Institute.

\section{References}

Arkes, J., \& Shen, Y-C. (2013) For better or for worse, but how about a recession? Contemporary Economic Policy. doi: 10.1111/coep.12029.

Blanchflower, D. G., Bell, D. N. F., Montagnoli, A., \& Moro, M. (2013). The effects of macroeconomic shocks on wellbeing. Working Paper, Dartmouth College, USA.

Blanchflower, D., \& Oswald, A. (2007). Is well-being U-shaped over the life cycle. Discussion Paper IZA 3075, Bonn, Germany.

Bridges, S., \& Disney, R. (2010). Debt and depression. Journal of Health Economics, 29, $388-403$. 
Brown, S., Taylor, K., \& Wheatley-Price, S. (2005). Debt and distress: evaluating the psychological cost of credit, Journal of Economic Psychology, 26, 642--63.

Cameron, A. C., \& Trivedi, P.K. (2005). Microeconometrics. New York: Cambridge University Press.

Caroleo, F. E., \& Pastore, F. (2011). Overeducation, earnings and job satisfaction in the graduate labour market, Working Paper, University of Naples, Italy.

Clark, A. E. (2003). Unemployment as a social norm: psychological evidence from panel data. Journal of Labor Economics, 21, 323-351.

Clark, A. E., Knabe, A., \& Ratzel, S. (2010). Boon or bane? Others' unemployment, wellbeing and job insecurity. Labour Economics, 17, 52-61.

Deaton, A. (2012). The financial crisis and the well-being of Americans. Oxford Economic Papers, 64, 1-26.

Ferrer-i-Carbonell, A., \& Frijters P. (2004). How important is methodology for the estimates of the determinants of happiness? Economic Journal, 114, 641-659.

Fleming, C., \& Kler, P. (2008). I'm too clever for this job: A bivariate probit analysis on overeducation and job satisfaction in Australia. Applied Economics, 40, 11231138.

Gandelman, N., \& Piani, G. (2013). Quality of life satisfaction among workers and nonworkers in Uruguay. Social Indicators Research, 111, 97 - 115.

Graham, C., Chattopadhyay, S., \& Picon, M. (2010). Adapting to adversity: happiness and the 2009 economic crisis in the United States. Social Research, 77, 715-748. 
Green, C., \& Leeves, G. (2013). Job security, financial security and worker well-being: new evidence on the effects of flexible employment. Scottish Journal of Political Economy, 60, $121-138$.

Hartog, J. (2000). Overeducation and earnings: where are we, where should we go? Economics of Education Review, 19, 131-147.

Hayes, J., \& Hartmann, H. (2011). Women and men living on the edge: economic insecurity after the Great Recession. Report \#C386, Washington D.C.: Institute for Women's Policy Research, USA.

Lancaster T. (2000). The incidental parameters problem since 1948. Journal of Econometrics, 95, 391-414.

Mavromaras, K., Sloane, P., \& Wei, Z. (2012). The Role of Education Pathways in the Relationship between Job Mismatch, Wages and Job Satisfaction: A Panel Estimation Approach. Education Economics, 20, 303-321.

McGuinness, S. (2006). Overeducation in the labour market. Journal of Economic Survey, $20,387-417$.

Metcalf, R., Powdthavee, N., \& Dolan, P. (2011). Destruction and distress: using a quasiexperiment to show the effects of the September 11 attacks on mental well-being in the United Kingdom. The Economic Journal, 121, F81-F103.

Mundlak, Y. (1978). On the pooling of time series and cross section data. Econometrica, 46, $69-85$.

Origo, F., \& Pagani, L. (2009). Flexicurity and job satisfaction in Europe: The importance of perceived and actual job stability for well-being at work. Labour Economics, 16, 547-555. 
Pesko, M. F. (2013). Stress and Smoking: Associations with Terrorism and Causal Impact. Contemporary Economic Policy, forthcoming.

Piero, J. M., Agut, S., \& Grau, R. (2011). The Relationship Between Overeducation and Job Satisfaction Among Young Spanish Workers: The Role of Salary, Contract of Employment, and Work Experience. Journal of Applied Social Psychology, 40, $666-689$.

Piper, A. (2012). Heaven knows I'm miserable now: overeducation and reduced life satisfaction. MPRA Paper No. 46926, Munich Personal RepEc Archive, Germany.

Reserve Bank of Australia (2008). Statement on Monetary Policy, November 2008, Sydney, Australia.

Reserve Bank of Australia (2009). Statement on Monetary Policy, November 2009, Sydney, Australia. 
Table 1 Job Satisfaction Measures: Summary Statistics

\begin{tabular}{|l|l|l|l|l|l|l|l|l|}
\hline & \multicolumn{9}{|c|}{ Age: 16-64 } \\
\hline & \multicolumn{2}{|c|}{ Overall } & \multicolumn{2}{c|}{ Pay } & \multicolumn{2}{c|}{ Job Security } & \multicolumn{2}{c|}{ Work } \\
\hline & Overed. & Non-Ov. & Overed. & Non-Ov. & Overed. & Non-Ov. & Overed. & Non-Ov. \\
\hline $2001-07$ & $7.36 * * *$ & 7.57 & $6.73 * * *$ & 7.04 & $7.79 * * *$ & 7.99 & $7.40^{* * *}$ & 7.63 \\
& $(1.88)$ & $(1.71)$ & $(6.73)$ & $(2.01)$ & $(2.19)$ & $(2.09)$ & $(1.96)$ & $(1.79)$ \\
\hline Obs. & 2911 & 11128 & 2911 & 11128 & 2911 & 11128 & 2911 & 11128 \\
\hline $2008-11$ & $7.44 * * *$ & 7.60 & $6.91 * * *$ & 7.14 & $7.87 * * *$ & 8.10 & $7.38^{* * *}$ & 7.61 \\
& $(1.73)$ & $(1.61)$ & $(2.02)$ & $(1.90)$ & $(2.05)$ & $(1.84)$ & $(1.89)$ & $(1.73)$ \\
\hline Obs. & 1649 & 6242 & 1649 & 6242 & 1649 & 6242 & 1649 & 6242 \\
\hline
\end{tabular}

$* * *, * *$ and $*$ indicate 1,5 and $10 \%$ levels of significance respectively. T-tests run in order to compare statistical significance between overeducated and non-overeducated individuals. Standard errors are in parenthesis. 
Table 2 Random Effects Ordered Probit (With Mundlak Corrections) Results

\begin{tabular}{|c|c|c|c|c|}
\hline & \multicolumn{4}{|c|}{$2001-7$} \\
\hline & Overall & Pay & Job Security & Work \\
\hline Overeducated & $-0.13 * * *(0.03)$ & $-0.12 * * *(0.03)$ & $-0.10 * * *(0.03)$ & $-0.11(0.03)$ \\
\hline Log of hourly wage & $0.31 * * *(0.04)$ & $1.18 * * *(0.04)$ & $-0.06(0.04)$ & $0.02(0.04)$ \\
\hline Part-time & $-0.13 * *(0.06)$ & $-0.17 * * *(0.06)$ & $-0.27 * * *(0.06)$ & $-0.02(0.06)$ \\
\hline Tenure: occupation & $-0.03 * * *(0.01)$ & $-0.01 *(0.01)$ & $-0.00(0.01)$ & $-0.03 * * *(0.01)$ \\
\hline Tenure: employer & $-0.05 * * *(0.01)$ & $-0.03 * * *(0.01)$ & $0.01(0.01)$ & $-0.02 * * *(0.01)$ \\
\hline Years Worked & $-0.00(0.01)$ & $-0.04 * * *(0.01)$ & $-0.01(0.01)$ & $-0.00(0.01)$ \\
\hline Years Unemployed & $0.04(0.05)$ & $-0.09 *(0.05)$ & $-0.07(0.05)$ & $0.08(0.05)$ \\
\hline Years Not in LF & $0.02(0.03)$ & $-0.01(0.03)$ & $-0.03(0.03)$ & $-0.02(0.03)$ \\
\hline $\mathrm{LR} \mathrm{Chi}^{2}$ & $607.12 * * *$ & $1342.38 * * *$ & $648.69 * * *$ & $471.30 * * *$ \\
\hline \multirow[t]{2}{*}{ Observations } & \multicolumn{4}{|c|}{14,039} \\
\hline & \multicolumn{4}{|c|}{$2008-11$} \\
\hline Overeducated & $-0.05(0.05)$ & $-0.05(0.05)$ & $-0.11 * *(0.05)$ & $-0.10 * *(0.05)$ \\
\hline Log of hourly wage & $0.33 * * *(0.07)$ & $1.14 * * *(0.06)$ & $-0.04(0.07)$ & $-0.14 * *(0.07)$ \\
\hline Part-time & $-0.01(0.09)$ & $-0.33 * * *(0.08)$ & $-0.01(0.09)$ & $-0.10(0.09)$ \\
\hline Tenure: occupation & $-0.01(0.01)$ & $-0.00(0.01)$ & $-0.00(0.01)$ & $-0.01(0.01)$ \\
\hline Tenure: employer & $-0.04 * * *(0.01)$ & $-0.03 * * *(0.01)$ & $0.01(0.01)$ & $-0.01(0.01)$ \\
\hline Years Worked & $-0.02(0.02)$ & $-0.03(0.02)$ & $-0.02(0.02)$ & $-0.02(0.02)$ \\
\hline Years Unemployed & $0.09(0.10)$ & $-0.02(0.09)$ & $-0.18 *(0.10)$ & $0.13(0.10)$ \\
\hline Years Not in LF & $0.01(0.06)$ & $0.01(0.06)$ & $0.07(0.06)$ & $0.06(0.06)$ \\
\hline $\mathrm{LR}_{\mathrm{Chi}}{ }^{2}$ & $323.43 * * *$ & $755.15^{* * *}$ & $444.85^{* * *}$ & $321.30 * * *$ \\
\hline Observations & \multicolumn{4}{|c|}{7,891} \\
\hline
\end{tabular}

$* * *, * *$ and $*$ indicate 1, 5 and $10 \%$ levels of significance respectively. Robust standard errors in parentheses. Omitted variables are age group dummies, time dummies, English speaking background status, marital status, health status, union membership, supervisory role, industry dummies, firm size, urban dummy, presence of children at home dummy and tertiary education dummy. The base case is an individual who is not overeducated, working full-time. 
Table 3 Random Effects Generalised Least Squares (With Mundlak Corrections) Results

\begin{tabular}{|c|c|c|c|c|}
\hline & \multicolumn{4}{|c|}{$2001-7$} \\
\hline & Overall & Pay & Job Security & Work \\
\hline Overeducated & $-0.18 * * *(0.04)$ & $-0.16 * * *(0.05)$ & $-0.15 * * *(0.05)$ & $-0.17 * * *(0.05)$ \\
\hline Log of hourly wage & $0.37 * * *(0.06)$ & $1.63 * * *(0.08)$ & $-0.11(0.08)$ & $0.03(0.06)$ \\
\hline Part-time & $-0.23 * *(0.09)$ & $-0.33 * * *(0.10)$ & $-0.44 * * *(0.12)$ & -0.01(0.09) \\
\hline Tenure: occupation & $-0.03 * * *(0.01)$ & $-0.02 * *(0.01)$ & $-0.00(0.01)$ & $-0.04 * * *(0.01)$ \\
\hline Tenure: employer & $-0.06 * * *(0.01)$ & $-0.04 * * *(0.01)$ & $0.00(0.01)$ & $-0.03 * * *(0.01)$ \\
\hline Years Worked & $0.00(0.02)$ & $-0.06 * * *(0.02)$ & $-0.01(0.02)$ & $-0.00(0.02)$ \\
\hline Years Unemployed & $0.06(0.07)$ & $-0.12(0.08)$ & $-0.13(0.09)$ & $0.13 *(0.07)$ \\
\hline Years Not in LF & $0.02(0.04)$ & $-0.01(0.05)$ & $-0.03(0.05)$ & $-0.01(0.04)$ \\
\hline Wald Chi $^{2}$ & $525.99 * * *$ & $1147.98 * * *$ & $653.87 * * *$ & $440.98 * * *$ \\
\hline \multirow[t]{2}{*}{ Observations } & \multicolumn{4}{|c|}{14,039} \\
\hline & \multicolumn{4}{|c|}{$2008-11$} \\
\hline Overeducated & $-0.07(0.06)$ & $-0.07(0.06)$ & $-0.16 * *(0.06)$ & $-0.13 * *(0.06)$ \\
\hline Log of hourly wage & $0.36^{* * *}(0.08)$ & $1.40 * * *(0.10)$ & $-0.01(0.09)$ & $0.18 * *(0.08)$ \\
\hline Part-time & $-0.10(0.12)$ & $-0.52 * * *(0.14)$ & $-0.06(0.13)$ & $-0.19(0.13)$ \\
\hline Tenure: occupation & $-0.01(0.01)$ & $-0.01(0.01)$ & $-0.00(0.01)$ & $-0.00(0.01)$ \\
\hline Tenure: employer & $-0.05 * * *(0.01)$ & $-0.05 * * *(0.01)$ & $0.01(0.01)$ & $-0.02(0.01)$ \\
\hline Years Worked & $-0.01(0.02)$ & $-0.03(0.03)$ & $-0.03(0.03)$ & $-0.02(0.02)$ \\
\hline Years Unemployed & $0.08(0.12)$ & $-0.13(0.14)$ & $-0.24 *(0.14)$ & $0.11(0.12)$ \\
\hline Years Not in LF & $0.01(0.07)$ & $0.03(0.08)$ & $0.12(0.09)$ & $0.07(0.07)$ \\
\hline Wald Chi $^{2}$ & $314.81 * * *$ & $649.88 * * *$ & $429.09 * * *$ & $299.71 * * *$ \\
\hline Observations & \multicolumn{4}{|c|}{7,891} \\
\hline
\end{tabular}

$* * *, * *$ and $*$ indicate 1,5 and $10 \%$ levels of significance respectively. Robust standard errors in parentheses. Omitted variables are age group dummies, time dummies, English speaking background status, marital status, health status, union membership, supervisory role, industry dummies, firm size, urban dummy, presence of children at home dummy and tertiary education dummy. The base case is an individual who is not overeducated, working full-time. 
Table 4 Random Effects Ordered Probit (Mundlak Corrections) - Partnered

\begin{tabular}{|c|c|c|c|c|}
\hline & \multicolumn{4}{|c|}{$2001-7$} \\
\hline & Overall & Pay & Job Security & Work \\
\hline Overeducated & $-0.08 * *(0.04)$ & $-0.14 * * *(0.04)$ & $-0.06(0.04)$ & $-0.09 * *(0.04)$ \\
\hline Log of hourly wage & $0.38 * * *(0.05)$ & $1.16^{* * *}(0.05)$ & $-0.004(0.05)$ & $0.09 *(0.05)$ \\
\hline Part-time & $-0.13 *(0.78)$ & $-0.17 * * *(0.07)$ & $-0.28 * * *(0.07)$ & $0.01(0.07)$ \\
\hline Tenure: occupation & $-0.03 * * *(0.006)$ & $-0.008(0.006)$ & $0.003(0.006)$ & $-0.03 * * *(0.006)$ \\
\hline Tenure: employer & $-0.05^{* * *}(0.008)$ & $-0.03 * * *(0.0007)$ & $-0.000(0.008)$ & $-0.02 * * *(0.008)$ \\
\hline Years Worked & $0.005(0.02)$ & $-0.02(0.02)$ & $-0.01(0.02)$ & $-0.004(0.02)$ \\
\hline Years Unemployed & $-0.04(0.02)$ & $-0.15 *(0.08)$ & $-0.006(0.09)$ & $0.06(0.09)$ \\
\hline Years Not in LF & $-0.012(0.04)$ & $-0.03(0.03)$ & $-0.04(0.04)$ & $-0.03(0.03)$ \\
\hline LR Chi $^{2}$ & $449.36^{* * *}$ & $960.56^{* * *}$ & $481.41 * * *$ & $314.24 * * *$ \\
\hline Overeducated (GLS) & $-0.11 * *(0.05)$ & $-0.18 * * *(0.06)$ & $-0.08(0.06)$ & $-0.11 * *(0.06)$ \\
\hline $\begin{array}{l}\text { Overeducated (GLS) } \\
\text { (partnered with } \\
\text { children) }\end{array}$ & $-0.16^{* * *}(0.06)$ & $-0.22 * * *(0.07)$ & $-0.08(0.07)$ & $-0.14 * *(0.06)$ \\
\hline \multirow[t]{2}{*}{ Observations } & \multicolumn{4}{|c|}{10,213} \\
\hline & \multicolumn{4}{|c|}{$2008-11$} \\
\hline Overeducated & $-0.06(0.05)$ & $-0.06(0.05)$ & $-0.17 * * *(0.06)$ & $-0.09 *(0.06)$ \\
\hline Log of hourly wage & $0.32 * * *(0.08)$ & $1.12 * * *(0.08)$ & $-0.02(0.08)$ & $0.18 * *(0.08)$ \\
\hline Part-time & $0.14(0.11)$ & $-0.21 * *(0.11)$ & $-0.06(0.11)$ & $-0.01(0.11)$ \\
\hline Tenure: occupation & $-0.01(0.01)$ & $0.0002(0.008)$ & $-0.007(0.008)$ & $-0.006(0.008)$ \\
\hline Tenure: employer & $-0.03 * * *(0.01)$ & $-0.03 * * *(0.01)$ & $0.005(0.01)$ & $-0.01(0.01)$ \\
\hline Years Worked & $0.01(0.02)$ & $-0.003(0.02)$ & $-0.01(0.02)$ & $0.003(0.02)$ \\
\hline Years Unemployed & $-0.01(0.13)$ & $-0.20(0.13)$ & $-0.06(0.14)$ & $0.004(0.13)$ \\
\hline Years Not in LF & $-0.01(0.07)$ & $0.04(0.07)$ & $0.05(0.08)$ & $0.07(0.07)$ \\
\hline $\mathrm{LR} \mathrm{Chi}^{2}$ & $252.03 * * *$ & $587.68 * * *$ & $358.93 * * *$ & $226.19 * * *$ \\
\hline Overeducated (GLS) & $-0.08(0.07)$ & $-0.07(0.07)$ & $-0.21 * * *(0.07)$ & $-0.11 *(0.07)$ \\
\hline $\begin{array}{l}\text { Overeducated (GLS) } \\
\text { (partnered with } \\
\text { children) }\end{array}$ & $-0.09(0.08)$ & $-0.11(0.08)$ & $-0.24 * * *(0.08)$ & $-0.14 *(0.07)$ \\
\hline Observations & & & & \\
\hline
\end{tabular}

***, ** and * indicate 1, 5 and $10 \%$ levels of significance respectively. Notes: See Table 2. 
Table 5 Random Effects Ordered Probit (Mundlak Corrections)- Singles

\begin{tabular}{|c|c|c|c|c|}
\hline & \multicolumn{4}{|c|}{$2001-7$} \\
\hline & Overall & Pay & Job Security & Work \\
\hline Overeducated & $-0.18 * * *(0.06)$ & $-0.04(0.06)$ & $-0.19 * * *(0.06)$ & $-0.16 * * *(0.06)$ \\
\hline Log of hourly wage & $0.22 * * *(0.08)$ & $1.21 * * *(0.08)$ & $-0.15^{*}(0.08)$ & $-0.13(0.08)$ \\
\hline Part-time & $-0.13(0.09)$ & $-0.18 * *(0.09)$ & $-0.22 * * *(0.09)$ & $-0.08(0.09)$ \\
\hline Tenure: occupation & $-0.05 * * *(0.01)$ & $-0.007(0.01)$ & $0.02(0.01)$ & $-0.04 * * *(0.01)$ \\
\hline Tenure: employer & $-0.04 * *(0.01)$ & $-0.05 * * *(0.02)$ & $0.02(0.02)$ & $-0.02(0.01)$ \\
\hline Years Worked & $-0.02(0.02)$ & $-0.04 *(0.02)$ & $0.02(0.02)$ & $-0.001(0.02)$ \\
\hline Years Unemployed & $-0.002(0.07)$ & $-0.13 *(0.07)$ & $-0.03(0.12)$ & $0.008(0.08)$ \\
\hline Years Not in LF & $0.07(0.06)$ & $0.09 *(0.06)$ & $0.02(0.06)$ & $0.05(0.06)$ \\
\hline $\mathrm{LR} \mathrm{Chi}^{2}$ & $262.87 * * *$ & $487.47 * * *$ & $294.19 * * *$ & $217.30 * * *$ \\
\hline Overeducated (GLS) & $-0.27 * * *(0.09)$ & $-0.07(0.09)$ & $-0.30 * * *(0.10)$ & $-0.27 * * *(0.09)$ \\
\hline \multirow[t]{2}{*}{ Observations } & \multicolumn{4}{|c|}{3,826} \\
\hline & \multicolumn{4}{|c|}{ 2008-11 } \\
\hline Overeducated & $0.03(0.10)$ & $0.07(0.09)$ & $0.06(0.10)$ & $-0.07(0.10)$ \\
\hline Log of hourly wage & $0.43 * * *(0.12)$ & $1.25 * * *(0.11)$ & $-0.005(0.12)$ & $0.17(0.12)$ \\
\hline Part-time & $-0.27 *(0.14)$ & $-0.47 * * *(0.14)$ & $0.19(0.14)$ & $-0.27 *(0.15)$ \\
\hline Tenure: occupation & $-0.02(0.02)$ & $-0.03(0.02)$ & $0.02(0.02)$ & $-0.005(0.02)$ \\
\hline Tenure: employer & $-0.05 * *(0.02)$ & $-0.05 * *(0.02)$ & $0.01(0.02)$ & $0.005(0.02)$ \\
\hline Years Worked & $-0.09 * * *(0.04)$ & $-0.04(0.03)$ & $-0.05(0.04)$ & $-0.08 * *(0.04)$ \\
\hline Years Unemployed & $0.24 *(0.14)$ & $0.19(0.13)$ & $-0.17(0.14)$ & $-0.34 *(0.20)$ \\
\hline Years Not in LF & $0.07(0.11)$ & $-0.04(0.11)$ & $0.14(0.11)$ & $0.11(0.11)$ \\
\hline $\mathrm{LR} \mathrm{Chi}^{2}$ & $151.13 * * *$ & $269.00 * * *$ & $175.27 * * *$ & $157.01 * * *$ \\
\hline Overeducated (GLS) & $0.06(0.12)$ & $0.08(0.14)$ & $0.03(0.14)$ & $-0.13(0.14)$ \\
\hline Observations & & & & \\
\hline
\end{tabular}

\footnotetext{
$* * *, * *$ and $*$ indicate 1,5 and $10 \%$ levels of significance respectively. Notes: See Table 2.
} 
Table 6 Job and Financial Stability

\begin{tabular}{|c|c|c|c|c|c|c|c|}
\hline & \multicolumn{7}{|c|}{$\%$ chance of being sacked in next 12 months } \\
\hline & & & & & \multicolumn{3}{|c|}{ OLS (Mundalk corrections) } \\
\hline & \multicolumn{2}{|c|}{ Full sample } & \multicolumn{2}{|c|}{ Partnered } & & Full sample & Partnered \\
\hline & Overed. & $\begin{array}{l}\text { Non- } \\
\text { Ov. }\end{array}$ & Overed. & Non-Ov. & & & \\
\hline $2001-07$ & 11.14 & 10.53 & 10.72 & 9.99 & Overed & $0.35(0.52)$ & $0.16(0.60)$ \\
\hline Obs. & 2908 & 11118 & 2065 & 8142 & & 14026 & 10207 \\
\hline $2008-11$ & 11.28 & 9.63 & 10.71 & 8.99 & Overed & $1.83 * *(0.61)$ & $1.81 * * *(0.68)$ \\
\hline \multirow[t]{5}{*}{ Obs. } & 1638 & 6229 & 1263 & 4574 & & 7867 & 5837 \\
\hline & \multicolumn{7}{|c|}{ Pay off credit card balances } \\
\hline & & & & & RE Orc & ed Probit $(\mathrm{Mu}$ & lk corrections) \\
\hline & \multicolumn{2}{|c|}{ Full sample } & \multicolumn{2}{|c|}{ Partnered } & & Full sample & Partnered \\
\hline & Overed. & $\begin{array}{l}\text { Non- } \\
\text { Ov. }\end{array}$ & Overed. & Non-Ov. & & & \\
\hline $2001-07$ & 3.78 & 3.89 & 3.84 & 3.95 & Overed & $0.00(0.07)$ & $-0.04(0.08)$ \\
\hline Obs. & 1342 & 5213 & 1028 & 4159 & & 6555 & 5187 \\
\hline $2008-11$ & 3.83 & 3.94 & 3.88 & 3.98 & Overed & $0.01(0.11)$ & $-0.02(0.13)$ \\
\hline Obs. & 798 & 3023 & 654 & 2445 & & 3821 & 3099 \\
\hline
\end{tabular}

*** and ** indicate 1 and 5\% levels of significance respectively. Notes: See Table 4. 


\section{APPENDIX}

Appendix Box 1 Workplace Satisfaction Question in the HILDA Questionnaire

E36 I now have some questions about how satisfied or dissatisfied you are with different aspects of your job.

If not currently employed: These questions refer to the most recent job you were working in the last 7 days.

I am going to read out a list of different aspects of your job and, using the scale on SHOWCARD 36, I want you to pick a number between 0 and 10 to indicate how satisfied or dissatisfied you are with the following aspects of your job. The more satisfied you are, the higher the number you should pick. The less satisfied you are, the lower the number.

a Your total pay

b Your job security

c The work itself (what you do)

d The hours you work

e The flexibility available to balance work and non-work commitments

f All things considered, how satisfied are you with your job? 
Appendix Table A1 Data Description

\begin{tabular}{|c|c|}
\hline Variable & Description \\
\hline Overall Job Satisfaction & $\begin{array}{l}\text { Ordinal variable ranging from } 0-10 \text { describing an individual's } \\
\text { overall satisfaction with their job }\end{array}$ \\
\hline Satisfaction with Pay & $\begin{array}{l}\text { Ordinal variable ranging from } 0-10 \text { describing an individual's } \\
\text { satisfaction with their pay }\end{array}$ \\
\hline Satisfaction with Job Security & $\begin{array}{l}\text { Ordinal variable ranging from } 0-10 \text { describing an individual's } \\
\text { satisfaction with their job security }\end{array}$ \\
\hline Satisfaction with (type of) Work & $\begin{array}{l}\text { Ordinal variable ranging from } 0-10 \text { describing an individual's } \\
\text { satisfaction with the type of work they undertake }\end{array}$ \\
\hline Overeducated & $\begin{array}{l}\text { Individual possesses qualifications in excess of the minimum } \\
\text { required to undertake their job. }\end{array}$ \\
\hline Age 16-24 & Individual is aged between 16 to 24 years \\
\hline Age 25-34 & Individual is aged between 25 to 34 years \\
\hline Age 35-44 & Individual is aged between 35 to 44 years \\
\hline Age 45-54 & Individual is aged between 45 to 54 years \\
\hline Age 55-64 & Individual is aged between 55 to 64 years \\
\hline Age 16-24 & Individual is aged between 16 to 24 years \\
\hline Wave 1 to Wave 11 & Individual was interviewed in 2001 to 2011 \\
\hline Couple & Individual is either married or in a de facto relationship \\
\hline ESB & Individual is an English Speaking Background immigrant \\
\hline NESB & Individual is a Non-English Speaking Background immigrant \\
\hline Poor Health & Individual has long-term health issues \\
\hline Log of Hourly Wage & The log of hourly wage in real terms in 2001 dollars \\
\hline Part-time & Individual is engaged in part-time work ( $<35$ hours a week) \\
\hline Union & Individual is a union member \\
\hline Supervise & Individual has a supervisory role at work \\
\hline Tenure: Occupation & Tenure (in years) in current occupation \\
\hline Tenure: Occupation ${ }^{2}$ & Tenure (in years) in current occupation squared \\
\hline Tenure: Employer & Tenure (in years) with current employer \\
\hline Tenure: Employer & Tenure (in years) with current employer squared \\
\hline Years Worked & Time (in years) in paid work \\
\hline Years Worked $^{2}$ & Time (in years) in paid work squared \\
\hline Years Unemployed & Time (in years) unemployed and actively searching for work \\
\hline Years Unemployed $^{2}$ & $\begin{array}{l}\text { Time (in years) unemployed and actively searching for work } \\
\text { squared }\end{array}$ \\
\hline Years Not in LF & $\begin{array}{l}\text { Time (in years) out of the labour force (neither working nor } \\
\text { actively seeking work) }\end{array}$ \\
\hline Years Not in $\mathrm{LF}^{2}$ & $\begin{array}{l}\text { Time (in years) out of the labour force (neither working nor } \\
\text { actively seeking work) squared }\end{array}$ \\
\hline Small & Employed in firm with <20 employees \\
\hline Mid & Employed in firm with 20-99 employees \\
\hline Big & Employed in firm with 100 or more employees \\
\hline Kids & Have (a) child(ren) living at home \\
\hline Uni & Possess a degree or post-graduate qualification \\
\hline
\end{tabular}




\begin{tabular}{|l|l|}
\hline City & Individual lives in an urban area \\
\hline Industry Categoriess & \\
\hline Agrimin & Agriculture, forestry fishing and mining \\
\hline Manuf & Manufacturing \\
\hline Powconst & Electricity, gas, waste services and construction \\
\hline Trade & Wholesale and retail trade \\
\hline Party & Accommodation and food services \\
\hline Transport & Transport, postal and warehousing \\
\hline Comm & Information media and telecommunications \\
\hline Finprop & Finance, insurance, rental, hiring and real estate services \\
\hline Tech & Professional, scientific and technical services \\
\hline Admin & Administrative and support services \\
\hline Public & Public administration and safety \\
\hline Educ & Education and training \\
\hline Health & Health care and social assistance \\
\hline Misc & Arts, recreation and other services \\
\hline
\end{tabular}

